\title{
A cidade ideal e a geografi-cidade na escola
}

César Augusto Ferrari Martinez*

Nestor André Kaercher **

Resumo: O presente texto tem por objetivo discutir a importância da relação com a cidade no ensino de Geografia na escola de Ensino Fundamental Porto Alegre (EPA). Com base na música de Chico Buarque - A Cidade Ideal - estabelece-se uma reflexão sobre a relação dos jovens estudantes com os espaços públicos da cidade e a importância de se entendê-los a partir do conceito de Relaçóes com o Saber (CHARLOT, 1997). Também se aponta a importância da discussão sobre o conceito de rua enquanto espaço do não-privado e da escola enquanto lugar, espaço construtor de identidade. Coloca-se como fundamental o princípio da dialogicidade proposto por Freire (1994). Por fim, o texto preocupa-se em considerar a necessidade da construção de um novo conceito de cidadania, no qual os estudantes-cidadãos são mobilizados a pensarem a cidade ideal, a condição de cidadania que querem exercer.

Palavras-chave: Cidade, Ensino de Geografia, Relação com o saber.

\footnotetext{
Licenciado em Geografia (UFRGS), Mestrando em Ensino de Geografia (UFRGS). Professor da Rede Municipal de Ensino de Porto Alegre (RS). E-mail: cesarfmartinez@yahoo.com.br

** Licenciado em Geografia (UFRGS), Mestre em Educação (UFRGS), Doutor em Geografia Humana (USP). Professor da Faculdade de Educação e do Programa de Pós-Graduação em Geografia da UFRGS. E-mail: nestorandre@yahoo.com.br.
} 


\begin{abstract}
This paper aims to discuss the importance of the relationship between the city and the teaching of geography in the Porto Alegre Elementary School (EPA). Based on the music of Chico Buarque - A Cidade Ideal - provides a reflection on the relationship of young students at the city's public spaces and the importance to understand them from the concept of Relations with the Knowledge (CHARLOT, 1997). It also highlights the importance of discussion of the concept of the street while the non-private space and the school as constructor of identity. Arises as the fundamental principle of dialogicity proposed by Freire (1994). Finally, the text focuses on the need to consider the construction of a new concept of citizenship, where studentscitizens are mobilized to think the ideal city, the condition of citizens who want to exercise.
\end{abstract}

Keywords: City, Teaching of geography, Relationship with knowledge.

\title{
Palavras iniciais
}

O texto que apresentamos aqui constitui alguns dos estudos realizados na construção de uma proposta curricular para a Escola Municipal de Ensino Fundamental Porto Alegre (EPA). A EPA, instituição da Rede Municipal de Ensino de Porto Alegre, surge e especializa-se no atendimento dos jovens que se encontram em situação de extrema vulnerabilidade social, em especial daqueles que se apresentam em situação de rua-moradia.

O entendimento de que o conhecimento de mundo e o da escola se apresentam relacionados, embora não nitidamente, no cotidiano da escola, nos fez procurar entender melhor a relação entre a escola (representada aqui pelo conhecimento formal, sistematizado) e a cidade (representada pelo conhecimento proveniente das vivências destes jovens na rua e com a rua). Para isso, buscamos, na relação entre os sujeitos e a cidade, algumas de nossas respostas e, porque não dizer, até algumas novas perguntas. Sabendo que 
estudar a cidade é um dos objetivos de muitas pesquisas no campo do Ensino de Geografia, buscamos saber de que forma alguns autores vêm tratando do tema e pretendemos relacioná-los aos nossos propósitos. Entendemos, também, que não é só na concepção de cidade, rua, urbano que vamos encontrar nossas ideias, nem mesmo no estudo específico do que querem ou sabem esses sujeitos. Percebemos ser na relação entre os sujeitos e a cidade que se constituem ricos e fartos materiais de pesquisa e reflexão.

\section{A cidade ideal}

Àquela altura da estrada já éramos quatro amigos. Queríamos fazer um conjunto, bem. Queríamos ir juntos à cidade, muito bem. Só que, à medida que a gente ía caminhando, quando começamos a falar dessa cidade, fui percebendo que os meus amigos tinham umas ideias bem esquisitas sobre o que é uma cidade. Umas ideias atrapalhadas, cada ilusão. Negócio de louco... (HOLLANDA, 1977).

$\mathrm{O}$ trecho citado acima pertence à introdução da música $A$ Cidade Ideal, pertencente ao musical "Saltimbancos" de 1977, no qual quatro bichos - jumento, cachorro, galinha e gata - fogem de seus respectivos locais de origem para encontrarem a liberdade e a independência de serem artistas na cidade. $\mathrm{O}$ excerto lido pertence ao jumento - representando a racionalidade da realidade em contraponto ao ideário de seus parceiros. As projeçôes de como cada bicho via a cidade estava na dimensão do que sonhavam ser a "cidade ideal", ou seja, um espaço para onde convergiam todos os seus interesses, como no trecho abaixo, em que os personagens cachorro, galinha e gata representam as suas cidades ideais, respectivamente:

A cidade ideal dum cachorro

Tem um poste por metro quadrado

Não tem carro, não corro, não morro

E também nunca fico apertado 
A cidade ideal da galinha Tem as ruas cheias de minhoca A barriga fica tão quentinha Que transforma o milho em pipoca [...]

A cidade ideal de uma gata É um prato de tripa fresquinha Tem sardinha num bonde de lata Tem alcatra no final da linha

Todos os personagens saíram, no contexto da obra, de uma situação de opressão, abandono, tensionamento. Ao fugir, projetaram, na ida à cidade, um mundo fantasioso de salvação para as suas angúrias. $\mathrm{O}$ que confere à cidade esta condição de espaço de esperança? Uma explicação simplificada seja talvez o fato da cidade contituir-se de um espaço de convergências, assim, um espaço, também, de possibilidades.

É interessante pensar que a cidade é o espaço das convergências inevitáveis. Pessoas que não se conhecem, tecnologias e produtos inéditos, eventos sociais de diversas naturezas, multiculturalismo: elementos que se cruzam, sobrepõem-se, imbricam-se, permeiam-se e se confundem dentro desta imensa malha tecida nos ambientes urbanos. A cidade é, sem dúvida, um espaço que se constitui na dinâmica da sociedade, produzindo e reproduzindo um modo de vida que se identifica com esta dinâmica.

Para Milton Santos (2006, p. 216),

O fato, porém, é que, pela estruturação do seu território e do seu mercado - uno e múltiplo -, as cidades atuais, sobretudo as metrópoles, abertas a todos os ventos do mundo, não são menos individualizadas. Esses lugares, com a sua gama infinita de situações, são a fábrica de relações numerosas, frequentes e densas. O número de viagens internas é muitas vezes superior ao de deslocamentos para outros subespaços. Em condições semelhantes, as grandes cidades são muito mais buliçosas que as médias e pequenas. A cidade é o lugar onde há mais mobilidade e mais encontros. A anarquia atual da cidade grande lhe assegura um maior número de deslocamentos, enquanto a geração de relações interpessoais é ainda mais intensa. 
O ensino de Geografia vem tratando da temática da cidade a partir de uma série de estudos que busca retomar o assunto entre professores e acadêmicos. Diversos pesquisadores (Lana Cavalcanti, Sônia Castellar, Helena Callai, Nestor Kaercher) vêm produzindo livros e artigos que promovem a cidade enquanto um tópico articulador às aulas de Geografia. Mais do que isso, tem-se pensado a cidade a partir do conceito de uma cidade-educadora (CASTELLAR, 2009), em que, além dos conceitos básicos sobre as formas e estruturas urbanas, possamos pensar a cidade enquanto espaço de construção social das relações que desenvolvem nosso modo de vida, um modo de vida urbano. Mais do que um aglomerado de pessoas, a cidade generaliza um modo de vida.

\section{A maioria das populações vive em áreas urbanas e o campo, em muitos países, também está se 'urbanizando', em função das mudanças nas rela- ções de trabalho e produção. A cidade passa a ser compreendida não apenas como um conteúdo geográfico, um objeto disciplinar, mas como um objeto de vivência pessoal e de ensino. (CASTELLAR, 2009, p. 45)}

Essa dimensão pedagógica da cidade não se restringe à Geografia, mas é papel dos professores-geógrafos discutir e pensar a cidade e, fundamentalmente, a condição de ser um cidadão. Lefebvre (2001) defende que foi na separação cidadecampo e na definição da polis grega que surge a condição para o desenvolvimento da filosofia. A divisão do trabalho gerada a partir do crescimento das cidades permitiu o estabelecimento de uma atividade intelectual de racionalização sobre aquele espaço. $\mathrm{Na}$ cidade enquanto sede do logos e da razão política, onde os cidadãos eram aparentemente iguais e, ao mesmo tempo, as diferenças eram simultâneas, locava-se o espaço fecundo à análise do que se propunha a filosofia clássica: pensar a totalidade. Yves Lacoste (2010) relembra também a relação etimológica entre os termos polis [cidade] e política, relacionando como a origem da palavra também tem seu sentido geográfico-espacial. A cidade seria, nesse sentido, a espacialização das relações políticas.

Apesar das polis gregas já terem introduzido questões relativas à democracia nos seus modelos políticos, a origem do 
conceito de cidadania que conhecemos hoje está intimamente ligado ao surgimento da cidade burguesa europeia e ao desenvolvimento da própria classe burguesa nas metrópoles que cresciam no continente europeu. No entanto, pretendemos defender a ideia de que a cidadania não é apenas uma categoria burguesa, podendo ser redimensionada dentro de outras concepções teóricas.

Assim, propomos, como necessária, a discussão de outro modelo de cidadania que não se restrinja à luta de classes, mas que também considere a condição de disparidade em que se encontra a maior parcela da população urbana. $\mathrm{O}$ desenvolvimento da cidadania pode articular, ao mesmo tempo, as idealizações individuais e particulares dos sujeitos (aspectos subjetivos) e os interesses comuns da vida em grupo na escola, fábrica, bairro (aspectos coletivos).

Reafirmar o direito à cidade seja, talvez, uma das primeiras ações a se promover quando pensamos em não só ensinar a cidade, mas ensinar para a cidade. Cavalcanti (2009, p. 83) defende que:

\begin{abstract}
A defesa do direito à cidade para todos os seus habitantes parte do entendimento de que a produção do seu espaço é feita com a participação destes habitantes, obedecendo às suas particularidades e diferenças. Trata-se de defender a necessidade de uma cidade com gestão democrática, que busca mediar interesses e ações mais imediatos e elementares, nem por isso, menos importantes para a vida humana, do cotidiano de seus moradores.
\end{abstract}

A concepção de cidade aqui apresentada parte do pressuposto de que a crise do capitalismo confunde-se com a crise do modernismo e espacializa-se em uma crise urbana sem precedentes. Para Maria Flora Gonçalves (2005), a fragmentação do tecido sociopolítico-espacial torna-se a ruptura do diálogo no espaço do conflito, causando um radical aprofundamento da segregação, chegando à situação extrema de interditar a mobilidade espacial. Harvey $(2004$, p. 96), também atenta às transformações urbanas, defendendo a ideia de que a "[...] ficção, fragmentação, colagem, ecletismo, todos infundidos de um sentido de efemeridade e 
de caos, são, talvez, os temas que dominam as atuais práticas de arquitetura do projeto urbano". Com isso, o autor está se referindo à coexistência de múltiplas propostas que tentam, sem sucesso na maioria dos casos, ordenar o espaço urbano.

\section{Pensando a cidade ideal}

Retomando a letra de Chico Buarque, resolvemos pensar o ensino da Geografia sobre esta projeção da cidade ideal. Ora, dirão alguns, então devemos buscar a cidade ideal? Devemos retomar a discussão de que existe tal cidade, uma condição urbana ideal, um cidadão ideal? Não, a proposta deste texto não é fechar a discussão sobre um modelo urbano específico e pronto para ser generalizado: não temos tal pretensão, tampouco adotamos tal concepção.

A cidade ideal aqui aparece, como na música, como um exercício do sujeito olhar para a sua cidade e pensar: e, para mim, como seria a minha cidade ideal? O trabalho de sensibilização para a formação cidadã começa na tentativa de se perceber não só como é a cidade, mas como ela poderia ser. A realidade, muitas vezes, hostil das periferias e ruas de nossas grandes cidades já constitui limites suficientes à construção de um espaço de discussão que confira à cidade a condição de um espaço de diálogos e possibilidades.

Na própria música, há o contraponto da fantasia construída pela ida à cidade:

Atenção porque nesta cidade

Corre-se a toda velocidade

E atenção que o negócio está preto

Restaurante assando galeto [...]

Jumento é velho, velho e sabido

E por isso já está prevenido

A cidade é uma estranha senhora

Que hoje sorri e amanhã te devora 


\section{Atenção que o jumento é sabido \\ É melhor ficar bem prevenido \\ E olha, gata, que a tua pelica \\ Vai virar uma bela cuíca}

O texto acima, em oposição ao representado pelas falas dos outros bichos, sugere a impressão de cidade como espaço da insegurança, do improvável, da situação-limite, da hostilidade e atrocidade. Sem dúvida, é inegável que a sensação daquele que chega, sem nunca haver estado, à grande cidade é de, ao mesmo tempo, sentir-se maravilhado e devorado pela metrópole.

Há de se pensar, no entanto, o que nesta cidade contemporânea - sem querer aqui homogeneizar a diversidade pertinente a cada núcleo urbano - constitui-se enquanto espaço de possibilidade e de insegurança, pois é também no tensionamento entre estas versões que se constrói o modelo de cidade em que vivemos e a que aspiramos. Assim é, sem dúvida, importante discutir a relação de um conceito maior da cidade: o conceito de rua. Esta é, por excelência, o conceito ingente da cidade. A rua enquanto forma ou conteúdo é o que caracteriza o espaço urbano em suas múltiplas manifestações. Expressões como "traçado" e "malha" fazem referência ao riscado das ruas na cartografia da cidade. A rua é o que conecta os espaços, unindo pontos, bairros, regiões e, ao mesmo tempo, o que divide o espaço, separando estes mesmos pontos, bairros, regiões. A rua é o espaço das convergências, no qual pessoas, carros, ônibus, carroças e cachorros circulam abertamente e, por vezes, concomitantemente. A rua é também o local das segregações, apartando o que é veículo, o que é pedestre, o que é rio, o que é calçada: quase tudo é separado na rua.

Mas a rua também é conteúdo, ela expressa em sua materialidade as relações subjetivas às quais os sujeitos são submetidos e submetem. A rua simboliza o não-privado, a não-casa, o nãoindividual. Ir para a rua é estar em um espaço de convivência pública e mútua, é estar na dinâmica do coletivo. A rua, assim, pode ser também a praça, a esquina, a calçada, o viaduto ou o 
bueiro. Estar nela significa não estar onde se é o seu lugar, mas em outro lugar qualquer da cidade.

E quando a sua estada é, justamente, a própria rua? E quando se tem no banco da praça, na marquise do prédio, no meio-fio da calçada o seu local de residência, de identificação, de refúgio, o seu mocó ${ }^{1}$. Qual a relação das crianças e jovens com trajetórias nas ruas de Porto Alegre com o espaço público? Como a rua-moradia constitui-se dentro da dinâmica do espaço urbano? Como podem estes jovens apropriar-se de um espaço coletivo como sendo seu? Qual seria a sua cidade ideal?

Aqui, interpomos um paradoxo que não é novo, mas ainda não está obsoleto enquanto discussão: são os jovens que pertencem às ruas, ou as ruas que pertencem aos jovens? Pensamos que, curiosamente, este paradoxo também não é contraditório, é a simples expressão de uma relação mútua de pertencimento. A ação de nos lugarizar gera um sentimento de que o lugar nos tem, assim como temos ao lugar. Se, por motivo ou outro, estabelecemos determinado mocó como lugar e território, percebemos nele um limite para nossa espacialização. Portanto, pertencemos o lugar e ao lugar, em uma relação de interdependência.

É nesta na intensidade de encontros com o espaço da rua e com o espaço da escola, e na relação entre eles, que se concentram os esforços desta pesquisa. Saber como o conhecimento se constrói na relação e no diálogo das partes que compõem as identidades destes jovens e de que forma estas relações apresentam-se enquanto possibilidade de acesso ao conhecimento, de transformação deste conhecimento, de construção de novos conhecimentos - em suma, como se apresentam enquanto currículo.

Sem dúvida, a EPA fora forjada nas praças, calçadas e viadutos desta capital, buscando, em cada intervenção, a possibilidade de um diálogo. É, portanto, da rua que nasceram boa parte dos percursos que compuseram o que hoje se apresenta

"Mocó é uma expressão êmica usada para designar esconderijo e/ou moradias irregulares. 'Mocoziar' significa esconder". (LEMOS, 2002) 
enquanto estrutura curricular da escola. Pergunta-se, por reuniões e corredores, se será na rua, ainda, que estará o público da escola.

Desde que foram implantadas as Totalidades Finais ${ }^{2}$, cresceu a procura pela escola por estudantes que buscam a "aceleração" dos estudos. Além dos tradicionais estudantes em situação de rua-moradia, passaram também a integrar o corpo discente da EPA jovens em situação de abrigagem e/ou com vínculos fragilizados em suas escolas e comunidades. A escola (re)começou a se olhar para encontrar, assim como os próprios jovens, sua identidade.

Em 2009, o governo federal instituiu a Política Nacional para a População em Situação de Rua e o Comitê Intersetorial de Acompanhamento e Monitoramento desta população, através do Decreto 7.053 de 23 de Dezembro. Segundo o Parágrafo Único do artigo $1^{\circ}$ desta lei, é considerada População em Situação de Rua

O grupo populacional heterogêneo que possui em comum a pobreza extrema, os vínculos familiares interrompidos ou fragilizados e a inexistência de moradia convencional regular, e que utiliza os logradouros públicos e as áreas degradadas como espaço de moradia e de sustento, de forma temporária ou permanente, bem como as unidades de acolhimento para pernoite temporário ou como moradia provisória.(BRASIL, 2010)

Com base nesse dispositivo, pode-se entender a População em Situação de Rua dentro de parâmetros mais elaborados. Todo rompimento ou abalo com o vínculo familiar destes jovens pode suscitar um movimento à rua. Por rua, aqui, podemos entender tanto o movimento realizado pelos jovens de buscar as praças, becos, esquinas - sozinhos ou encontrando seus pares - como as ações que determinam a saída - permanente ou temporária - dos mesmos de suas residências. Não queremos aqui também homogeneizar os jovens que dormem em marquises de prédios com aqueles que se encontram em instituições de abrigagem,

2 A EPA é uma escola que funciona dentro da proposta de Totalidades do Conhecimento, característica do Ensino de Jovens e Adultos da Rede Municipal de Ensino de Porto Alegre. As Totalidades Finais correspondem à fase final do Ensino Fundamental. 
mas pretendemos mostrar que talvez a escola não tenha parado de atender a rua, talvez a esta é que tenha se transformado.

Lemos (2002) resgata a importância de considerarmos as vivências destes sujeitos que moram e circulam nas ruas. Diz a autora:

Quem olha as crianças perambulando pelo centro da cidade, dormindo sob marquises ou mendigando para sobreviver, pode pensar que elas nasceram do asfalto, que sempre estiveram lá. Afinal, já faz tanto tempo que vemos crianças, jovens e adultos dormindo pelas ruas que eles parecem compor o cenário da metrópole moderna. Mas estas pessoas nasceram como nós, de uma mãe, de um pai - presentes ou não. Estiveram, por um período vinculados, a uma comunidade, ou a uma instituição que lhes adotou desde bebês. Na maioria dos casos, teve uma experiência escolar.

Nascimento (2005, p. 40) chama a atenção de como "na sociedade brasileira, ainda é presente a imagem do espaço da rua como um espaço de roubos, de tragédias, de desavenças, de 'qualquer um'.” A situação de rua-moradia talvez deva ser entendida a partir da relação com a rua. Quando jovens estabelecem novos vínculos afetivos com os lugares, estabelecem novas relações e práticas espaciais. Institucionalizados ou não, eles veem na rua uma possibilidade de liberdade, ainda que relativa. Novamente em Nascimento (2005, p. 37), há a referência da rua como sendo o espaço do movimento, dos prazeres, dos vícios, das transgressões, em suma, de se aprender "as coisas da vida".

A simultaneidade de conteúdos e formas expressas nas ruas pode tecer na escola uma trama de ações e percepções que busquem identificar, entender e problematizar estes parâmetros. O exercício da escuta atenta de cada história, denúncia, relato, informação e, principalmente, de cada saber trazido por estes jovens-estudantes pode significar importantes ingredientes na condução das ações e reflexôes pedagógicas da EPA. 


\title{
O meu lugar na cidade, o meu lugar na escola
}

\author{
Milton Santos (2006, p. 218) considera o lugar como \\ [...] o quadro de uma referência pragmática ao mundo, do qual the vêm \\ solicitações e ordens precisas de açốes condicionadas, mas é também o \\ teatro insubstituível das paixões humanas, responsáveis, através da ação \\ comunicativa, pelas mais diversas manifestações da espontaneidade e \\ da criatividade.
}

O ato de lugarizar a escola passa por entendermos que ela traz em si os resultantes de um conjunto de ações técnicas - sendo, portanto, um meio técnico - e de relações interpessoais - sendo, portanto, um meio comunicacional. Assim, pretendemos estabelecer a dialogicidade enquanto prática fundamental na construção de propostas gestoras do conhecimento deste lugar-escola.

Bernard Charlot (1997, p.60) diz que

[...] adquirir saber permite assegurar um certo domínio do mundo no qual se vive, comunicar-se com os outros seres e partilhar o mundo com eles. [...] Assim, a definição do homem enquanto sujeito do saber se confronta com a pluralidade das relações que ele mantém com o mundo

"Existir, humanamente, é pronunciar o mundo, é modificálo". As palavras de Freire (1994, p. 44) refletem o significado do diálogo não enquanto apenas estratégia comunicativa, mas prática política de dizer a sua palavra, de pronunciar-se em um mundo de intensas transformações, como é, por exemplo, a cidade. O diálogo se sustenta enquanto uma prática entre sujeitos. $\mathrm{O}$ sujeito-cidadão aprende a pronunciar a cidade na medida em que aprender a dialogar com ela.

Cada escola produz infinitas possibilidades de diálogo com a cidade. Tantos são os diálogos quanto são as possibilidades de se relacionar com a cidade, a construção de identidades com os espaços urbanos e com a própria escola. Os processos educativos ocorrem na medida em que os sujeitos-cidadãos confrontam ideias entre o que se tem e o que se propóe em realidade. Desta 
forma, é tarefa inalienável dos professores-geógrafos promover os diálogos entre sujeito-cidadão e cidade e sujeito-cidadão e outros sujeitos-cidadãos.

Conforme identifica Cavalcanti (2008, p. 75), “[...] escola, por meio do ensino de Geografia, pode ser um lugar de encontro e confronto entre as diferentes formas de concepção e prática da cidade, cotidiana e científica”. Muitos professores-geógrafos identificam-se com o fato de sua disciplina ter como um dos objetivos o ensino do exercício da cidadania. Não podemos, dessa forma, negar que é a cidade o palco deste fazer-se cidadão. Ou ainda, é na relação com a cidade que cada um elabora, para si e para suas comunidades, o que é ser cidadão, a sua condição de cidadão-ideal, a sua cidade ideal.

\section{Da relação com a cidade}

Aqui, relembramos a origem etimológica da Geografia, sempre relacionada à composição das palavras Geo [Gaia, Terra] e Grapho [escrita, registro]. O sufixo $i$ a é usado no estabelecimento de uma relação entre as palavras, entre a escrita e a Terra, entre a escrita e o Mundo, se assim o preferir. Ora, põe-se uma provocação aos professores-geógrafos em relação a este significado: se ensinar Geografia é ensinar a descrever, registrar, escrever a Terra, é necessário também aprender a realizar a sua leitura.

Nada mais geográfico, portanto, do que o princípio básico de Freire de que a leitura do mundo precede a leitura da palavra. Claro que não queremos fazer aqui nenhuma qualidade de popdegradação (MORIN, 2003), sendo reducionistas na obra de Freire, e sim relacionar as palavras deste pensador à nossa prática no ensino desta ciência geográfica. Se percebemos a Geografia enquanto ciência que se propóe a olhar para o espaço, interpretálo, pensá-lo, transformá-lo - propomos que, na relação com a cidade, possamos estar colhendo recursos para desenvolver nossas ações pedagógicas. 
O diálogo que é previsto em Freire reitera uma relação muito mais profunda do que a "eu-tu", pois "nosso papel não é falar ao povo sobre nossa visão do mundo, ou tentar impô-la a ele, mas dialogar com ele sobre a sua e sobre a nossa (FREIRE, 1994, p. 49). Dialogar com a cidade não pode ser limitado a estabelecer parâmetros de exercício de cidadania, como se houvesse uma receita. É preciso que se construa - cotidianamente - as relações com os espaços urbanos com base na troca e desenvolvimento de experiências, vivências, conhecimentos e perspectivas sobre a cidade.

Fazendo-nos valer de várias ideias presentes na obra de Charlot (2007), consideramos, então, três dimensões educativas sobre o ensino da Geografia para/com a cidade, e suas perguntasgeradoras:

1. Da relação sujeito-cidadão/cidade: como o sujeito percebe os espaços urbanos em que interage e como se percebe enquanto partícipe destes espaços? Como o sujeito percebe a possibilidade de intervir, individual e coletivamente, nas dinâmicas impostas pelo modo de vida urbano? Que representaçôes implicam a relação entre este sujeito e a cidade, seus espaços, seus processos?

2. Da relação entre sujeitos-cidadãos: como ocorre o confronto e o encontro das ideias sobre a cidade? Como acontece e como pode acontecer o diálogo entre as diferentes propostas para a cidade entre estes sujeitos? Qual a intervenção que cabe aos professores-geógrafos nestes diálogos?

3. Da relação sujeitos-cidadãos com os saberes urbanos: quais são as figuras do aprender destes sujeitos-cidadãos sobre a cidade? Qual o sentido que estes sujeitoscidadãos percebem ao se relacionarem com o saber? Que elementos são significativos na mobilização destes sujeitos ao conhecimento? 
Estar no mundo é estar aprendendo, inclusive, a geografizar este mundo. Para Charlot $(2007$, p. 53), "[...] nascer, aprender, é entrar em um conjunto de relações e processos que constituem um sistema de sentido, onde se diz quem eu sou, quem é o mundo, quem são os outros". Temos, portanto, que estar submetido ao mundo é estar submetido à condição de aprender. No entanto, estas relaçóes com o que/como/quando/com quem se aprende são definidoras de como cada sujeito irá apropriar-se de seus conhecimentos.

Compreendemos as Relações com o Saber de Charlot como as existentes entre o aprender e as relações sociais (e aqui incluímos, por conta própria, espaciais) inerentes a este movimento de aprendizagem, não sendo possível entender o aprendizado sem considerar que existem tais relações. Sabendo da relação dos estudantes-cidadãos com a cidade, seria incoerente não pensarmos em uma aprendizagem na qual não houvesse espaço para as manifestações destas identidades. A estas relações entre o ensino de geografia e a relação com a cidade, chamamos geograficidades.

Seria a identidade espacial com a cidade o objeto que nos mobiliza a ensinar a geograficidade? Qual o caminho que deve ser percorrido para promover a dialogicidade, como propóe Freire, entre cidadãos, cidade e conhecimento?

Charlot (1997, p. 63), nos traz que

[...] as relações de saber são, mais amplamente, relações sociais. Essas relações de saber são necessárias para constituir o saber, mas, também, para apoiá-lo em sua construção: um saber só continua válido enquanto a comunidade científica o reconhecer como tal, enquanto uma sociedade continuar considerando que se trata de um saber que tem valor e que merece ser transmitido.

O que o autor deixa claro no trecho acima - ao definir o que considera as relaçóes com o saber - é de que não existe saber sem a relação entre o sujeito e o saber. Da mesma forma, nos traz que o sujeito não é isolado, individualizado. Do contrário, está inscrito em uma complexa rede de relações sociais, às quais se remete e é remetido. Da mesma forma, podemos inferir que este 
sujeito - enquanto sujeito espacial - é um sujeito que mantém uma relação com a cidade, estando também submetido a uma relação com o saber sobre esta cidade.

Assim, devemos nos preocupar em conhecer quem são estes sujeitos que aprendem na EPA. Quem vem à EPA? O que procura quando vem? O que percebe enquanto se está estudante? E o que percebem quando concluem o Ensino Fundamental? Qual a relação destes jovens com o aprendizado na EPA? De que forma usam estes saberes em suas relações com a cidade?

Paulo Freire (1994, p. 28-29), nos fala da importância da intersubjetividade na construção de uma Pedagogia do Oprimido. Diz ele:

[...] de tanto ouvirem de si mesmos que são incapazes, que não sabem nada, que não podem saber, que são enfermos, indolentes, que não produzem em virtude de tudo isto, terminam por se convencer de sua 'incapacidade'. [...] Ao defendermos um permanente esforço de reflexão dos oprimidos sobre suas condiçóes concretas, não estamos pretendendo um jogo divertido em nível puramente intelectual. Estamos convencidos, pelo contrário, de que a reflexão, se realmente reflexão, conduz à prática.

Freire ainda se preocupa - na Pedagogia do Oprimido em discernir "prática" de "práxis", sendo esta última a reflexão sobre a prática, reflexão sobre a ação - gerando uma nova ação. A práxis - ou a prática dotada de ação e reflexão - deve aparelhar os sujeitos a romper com suas situações-limite. Estas - para Freire - configuram-se enquanto obstáculos em que os oprimidos vislumbram-se como intransponíveis por encontrarem-se imersos em sua própria condição. A superação dessas barreiras, segundo Freire, depende, em grande parte, da educação libertadora, que faz emergir a possibilidade do ser-mais.

Charlot (1997) considera incoerente as sociologias que não contemplam a perspectiva sobre o sujeito. Sem querer torná-la psicologia, o autor defende que possamos considerar aspectos subjetivos sobre os fatos sociais. Para isso, defende a existência da leitura positiva sobre os sujeitos. Charlot considera que a 
perspectiva do "Fracasso Escolar" é uma leitura negativa pelas quais as categorias dominantes percebem os dominados. Para ele, é necessário que tenhamos consciência de que este sujeito que tem seu insucesso justificado nas carências, lacunas e exclusões é, na verdade, um sujeito dominado. Porém, ainda assim, um sujeito.

\section{Voltando à cidade ideal}

Mas não, mas não

O sonho é meu e eu sonho que

Deve ter alamedas verdes

A cidade dos meus amores

E, quem dera, os moradores

E o prefeito e os varredores

Fossem somente crianças

O refrão da música de Chico Buarque coroa a esperança como o elemento indispensável na ação cidadã. Tentando não fechar a discussão, mas encaminhá-la, entendemos que transformar a relação com a cidade é uma possibilidade dentre várias na construção da nossa cidade ideal. Ainda assim, aos que dirão que tal condição não existe, relembramos as palavras do pensador Eduardo Galeano (1994), sobre a utopia

Ela está no horizonte $[\ldots]-$ Me aproximo dois passos, ela se afasta dois passos. Caminho dez passos e o horizonte corre dez passos. Por mais que eu caminhe, jamais a alcançarei. Para que serve a utopia? Serve para isso: para caminhar

O objetivo de pensar a cidade ideal não é atingi-la de fato, mas mobilizar os estudantes-cidadãos ao conhecimento necessário para apropriarem-se da ação pela transformação. Nesse sentido, a disciplina de Geografia pode e deve exercer a sua geograficidade, a sua capacidade de transformar o espaço urbano a partir do seu conhecimento, da sua leitura de mundo e da sua práxis. A partir do que queremos para cidade, conseguiremos 
também avaliar o que queremos enquanto cidadãos, qual a nossa participação, nosso papel, nossas ações.

\section{Referências}

BRASIL. Decreto 7.053 de 23 de dezembro de 2009. Disponível em www.planalto.gov.br. Acesso em 12 de nov. de 2010.

CASTELLAR, Sônia Maria Vieira. Lugar de vivência: a cidade e a aprendizagem. In: PEREIRA, Marcelo Garrido. La espesura del lugar: reflexiones sobre el espacio em el mundo educativo. Chile: Universidad Academia del Humanismo Cristiano, 2009

CAVALCANTI, Lana. A geografia escolar e a cidade. Campinas: Papirus, 2008.

CAVALCANTI, Lana. A educação geografia e a formação de conceitos: a importância do lugar no ensino de geografia. In: PEREIRA, Marcelo Garrido. La espesura del lugar: reflexiones sobre el espacio em el mundo educativo. Chile: Universidad Academia del Humanismo Cristiano, 2009

CHARLOT, Bernard. Da relação com o saber (elementos para uma teoria). Porto Alegre: Artmed, 1997.

FREIRE, Paulo. Pedagogia do oprimido. Rio de Janeiro: Paz e Terra, 1994.

GALEANO, Eduardo. As palavras andantes. Porto Alegre: L\&PM, 1994.

GONÇALVES, Maria Flora. Ângulos da relação entre prática social e construção do espaço. In: CARLOS, Ana Fani Alessandri; LEMOS, Amália Inês Geraiges. Dilemas urbanos (Novas abordagens sobre a cidade). São Paulo: Contexto, 2005.

HARVEY, David. A condição pós-moderna: uma pesquisa sobre as origens da mudança cultural. São Paulo: Loyola, 2004.

LACOSTE, Yves. A geografia - isso serve em primeiro lugar para fazer a guerra. Campinas: Papirus, 2010.

LEFEBRVE, Henri. O direito à cidade. São Paulo: Centauro, 2004. 
LEMOS, Míriam Pereira. Ritos de entrada e ritos de saída da cultura de rua: trajetórias de jovens moradores de rua em Porto Alegre. Dissertação de Mestrado. Porto Alegre, UFRGS, 2002, $152 \mathrm{f}$.

MORIN, Edgar. Ciência com consciência. Rio de Janeiro: Bertrand Brasil, 2003.

NASCIMENTO, Carmem Teresinha Brunel do. A casa, a escola e a rua: espaços de múltiplas práticas sociais no cotidiano de meninos e meninas que frequentam três escolas públicas na periferia da cidade de Porto Alegre. Tese de Doutorado. Porto Alegre, UFRGS, 2005, $295 \mathrm{f}$.

SANTOS, Milton. A natureza do espaço (Técnica e Tempo, Razão e Emoção). São Paulo: EDUSP, 2006. 